\title{
VARIA FORTUNA DE UN TONO DE COMEDIANTES: «AMA AL QUE AMA, ANAJARTE», DE LA FIERA, EL RAYO, LA PIEDRA
}

\author{
DISPARATE FORTUNES OF A 'TONO DE COMEDIANTES': \\ “AMA AL QUE AMA, ANAJARTE”, FROM LA FIERA, EL RAYO, LA PIEDRA
}

\author{
Carmelo Caballero Fernández-Rufete \\ Universidad de Valladolid \\ rufete@fyl.uva.es \\ ORCID iD: https://orcid.org/0000-0002-0152-6042
}

\begin{abstract}
Resumen
La única fuente musical conocida hasta la fecha perteneciente al drama mitológico calderoniano La fi era, el rayo, la piedra corresponde a la intervención "Ama al que ama, Anajarte", cantada por Anteros en el momento en que el dios se presenta ante la desdeñosa reina de Trinacria, al fi nal de la segunda jornada. Aunque la fuente musical no está exenta de problemas, su localización y edición nos obliga a plantearnos el papel que La fiera... jugó en la interacción entre drama y música en la escena española durante la década central del siglo XVII. Al mismo tiempo, el estudio del tono cantado por Anteros nos da pie para rastrear la circulación, difusión y popularización de algunos tonos teatrales del barroco y su arraigo en otros repertorios, tanto religiosos como profanos.
\end{abstract}

\section{Palabras clave}

Calderón de la Barca, drama mitológico, fuentes musicales del teatro español del Siglo de Oro, contrafactum, villancico, tono humano, Miguel Gómez Camargo.

\section{LA MÚSICA DE LA FIERA, EL RAYO, LA PIEDRA: CUESTIONES GENERALES}

Tanto la crítica literaria como la musicológica están prácticamente de acuerdo sobre la gran importancia que el drama mitológico calderoniano Las durezas de Anajarte y el amor correspondido, más conocido como La fiera, el rayo, la piedra, tuvo en la escena española a mediados del siglo XVII; a pesar de la casi total ausencia de testimonios musicales que avalen las declaraciones de "novedad estilística" que

(C) 2018 CSIC. Este es un artículo de acceso abierto distribuido bajo los términos de una licencia de uso y distribución Creative Commons Attribution 4.0 International (CC BY 4.0)

Cómo citar este artículo/Citation: Caballero Fernández-Rufete, C. (2018). Varia fortuna de un tono de comediantes: «Ama al que ama, Anajarte», de la fiera, el rayo, la piedra. Anuario Musical, 73: 103-122. doi: http://dx.doi.org/10.3989/redc.2018.73.07

\begin{abstract}
The only musical source known to date of the Calderonian mythological drama La fiera, el rayo, la piedra corresponds to the intervention "Ama al que ama, Anajarte", sung by Anteros at the moment when the god appears before the disdainful queen of Trinacria, at the end of the second act. Although the musical source is not without problems, its location and edition force us to consider the role that La fiera... played in the interaction between drama and music in the Spanish scene during the middle decade of the 17-th century. At the same time, the study of the song of Anteros gives us the opportunity to trace the circulation, diffusion and popularization of some theatrical baroque songs and its links with other repertoires, both religious and secular.
\end{abstract}

\section{Key words}

Calderón de la Barca, mythological drama, musical sources of spanish Golden Age theatre, contrafactum, 'villancico', 'tono humano', Miguel Gómez Camargo.

se le atribuyen, no hay duda de que el estudio de sus aspectos musicales merece una mayor atención; la reconstrucción de una importante escena dramático-musical de la segunda jornada de la obra me ha parecido una ocasión adecuada para abordarlo.

Una vez más, las afirmaciones que se han vertido respecto al papel de la música en La fiera, el rayo, la piedra derivan - como tantas veces en los estudios musicales del teatro áureo- tanto del análisis de las rúbricas y didascalias que figuran en las diferentes ediciones antiguas de la obra como de 
ciertas inferencias derivadas de determinados documentos históricos ${ }^{1}$.

Sin embargo, al confrontar la lectura de la obra en la Tercera Parte de Comedias de D. Pedro Calderón de la Barca (Madrid, Domingo García Morrás, 1664) y de la correspondiente edición de la Tercera Parte de Comedias del célebre poeta español don Pedro Calderón de la Barca de Juan de Vera Tassis (Madrid, por Francisco Sanz, 1687) encontramos diferencias sustantivas, algunas de las cuales afectan al problema de la música, y particularmente a la introducción del estilo recitativo en el teatro español. Las afirmaciones generalistas que apuntan que por vez primera se prescribe el uso del recitativo en La fiera, el rayo, la piedra no ayudan demasiado a clarificar el problema ${ }^{2}$. Una vez examinadas detenidamente las rúbricas de ambas ediciones, podemos puntualizar que en la primera de ellas no existe ni una sola referencia al estilo recitativo, mientras que en la segunda sólo encontramos una rúbrica con referencia a tal estilo musical italiano, que precede al parlamento de Cupido "Si el orbe de la luna", de la segunda jornada. Es más, en el pasaje marcado por Vera Tassis como recitativo la editio princeps (1664) no prescribe ni tan siquiera el canto. Lo que en ese pasaje encontramos es la siguiente rúbrica: "Vase [Lebrón] y sale Cupido. / Cupido. Si el orbe de la Luna...!". Por tanto, queda meridianamente claro que la primera edición no prescribe explícitamente el recitativo.

Aunque hacia el final del artículo volveré sobre este tema todo parece apuntar - en ausencia de cualquier otro testimonio- a que la totalidad de las intervenciones musicales en $\mathrm{La}$ fiera, el rayo, la piedra fueron musicalizadas en el tradicional estilo español.

La documentación exhumada por Mina Bacci con respecto a la correspondencia de Baccio del Bianco nos revela interesantes aspectos que atañen tanto a la identidad del compositor de la música de La fiera, el rayo, la piedra como a las dificultades que encontró tal músico para introducir el estilo recitativo en las compañías teatrales españolas. Aunque la información que proporciona Baccio del Bianco es interesante y sugestiva, no deja de ser chocante la atribución de la música de La fiera, el rayo, la piedra a Domingo Scherdo, toledano, dado que es la única referencia que encontramos a este autor en la historia de la música española. Ya Stein subrayaba que este nombre - o alguna de las posibles variantes hipotéticas (Izquierdo, Esquerdo, Cerdo...) no ha aparecido hasta la fecha en ninguna otra documentación musical conocida ${ }^{3}$. En Toledo no se ha hallado información alguna en la documentación musical de la capilla catedralicia, y tampoco deja de resultar extraño que un compositor absolutamente desconocido (salvo quizá para Baccio del Bianco) recibiera el encargo de escribir la música para un drama mitológico tan emblemático - tanto por su interpretación frente a los monarcas

1 En este caso, particularmente de la correspondencia del escenógrafo Baccio del Bianco. A este respecto véase BACCI (1963): 68-77.

2 Así, la emitida por STEIN (1993): 135. Del mismo modo se manifiesta EGIDO (1989): 87-88.

3 STEIN (1993): 137. en una fiesta tan importante como por la novedad estilística que supuestamente pretendía introducir en la escena española.

Aunque no he sido capaz de sacar a la luz documentación nueva sobre Domingo Scherdo, sin embargo, sí he podido documentar una tenue conexión entre uno de los tonos de la segunda jornada de La fiera - en concreto, la sección cantada por Anteros, "El correspondido Amor"- y la producción musical del compositor Tomás Micieces, maestro de capilla que fue de la catedral primada de Toledo entre los años 1650 hasta $1661 . \mathrm{Me}$ refiero al villancico de Navidad, al Nacimiento, "sobre los tonos viejos”, ¡Escuchad! ¡Atención!, cuya sección de coplas está elaborada, como apunta el propio texto literario, "con principios de romances", donde se cita por dos veces el primer verso de las antedichas coplas de Anteros (cc. 237-242).

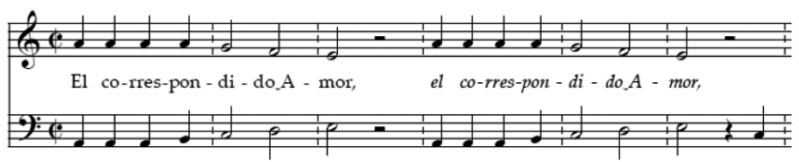

Ejemplo 1. $E$-SE 45/2, cc. 237-242

El villancico fue cantado en la catedral de Toledo $(\boldsymbol{E}-T c)$ la Navidad de $1656^{4}$, aunque en este caso la versión que hemos transcrito procede del archivo musical de la catedral de Segovia $(\boldsymbol{E}-S E)$. Por otra parte, a pesar de que Tomás Micieces no figura entre los corresponsales de Miguel Gómez Camargo, sí que contamos al menos con una noticia que pone de manifiesto que el maestro de Valladolid poseía algunas composiciones de Micieces y que distribuyó alguna de ellas por otras ciudades. En concreto, en la "Memoria de los papeles que doi para la Traslazión de la Birjen de la Peña [Tordesillas, 1688,]" Camargo escribió de su puño y letra una entrada que especifica: "Misas: una de Miziezes, a 8". No obstante, no creo que ni la cita ni el documento aportado sean motivo suficiente para justificar una atribución de la composición de la música de La fiera, el rayo, la piedra a Micieces.

Por otra parte, debemos recordar que, en la loa del siguiente drama mitológico calderoniano, Fortunas de Andrómeda y Perseo, el "recitar cantando" se presenta como una novedad. Podemos pensar que, al ser prácticamente los mismos espectadores los que presenciaron ambos estrenos en el estrecho lapso de un año, no tendría demasiado sentido presentar esa "otra armonía en la voz" de los dioses - tal y como aparece en Fortunas - como algo totalmente novedoso si se hubiera utilizado previamente en La fiera.

4 Villancicos al Nacimiento de nuestro Señor Iesu Christo que se cantaron la Noche Buena, en la santa Iglesia de Toledo, en este año de 1656, siendo en ella Maestro de Capilla Thomás Micieces, f. 2, Villancico segundo. Impresso en Toledo, por Francisco Calvo. Biblioteca Nacional de España, Madrid, E-Mn, VE-88/22. No obstante, la fuente musical se encuentra en el archivo musical de la catedral de Segovia $(\boldsymbol{E}-S E, 45 / 2)$, en donde aparece subtitulado como "Villancico sobre los tonos viejos".

5 CABALLERO (2004): 204. 
Mi impresión es que, efectivamente, un músico llamado Domingo Scherdo, venido a España probablemente con el nuncio Giulio Rospigliosi, y bajo las sugerencias o directrices de éste y la aquiescencia de Baccio del Bianco, trató de enseñar a un conjunto de músicos españoles, a partir de 1652, a cantar siguiendo "el estilo recitativo" en boga en Italia, tarea, por lo visto, tan dificultosa como poco gratificante, de modo que la asimilación de tal modo de cantar no debió estar lo suficientemente asentada como para ser utilizada de inmediato en La fiera, por lo que su introducción en una obra dramática se dilató hasta mayo de 1653, con el estreno de Fortunas, al mismo tiempo que Calderón de la Barca encontró un modo satisfactorio y coherente de justificar la introducción del recitativo como algo exclusivo de los dioses de la mitología. A pesar de ello, considero que el afianzamiento del estilo recitativo en la música española se dilató durante décadas.

\section{EL TONO "AMA AL QUE AMA, ANAJARTE"}

En $\boldsymbol{E}-V, 71 / 46^{6}$, f. 12, Miguel Gómez Camargo copió las siguientes melodías para tesitura de contralto, sin línea de acompañamiento continuo y con el único texto que se consigna en los ejemplos ${ }^{7}$ :

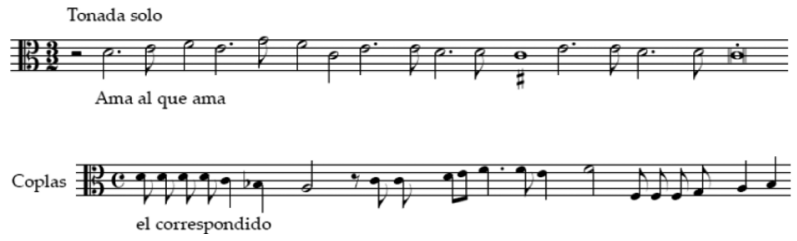

Ejemplos 2. y 3. $\boldsymbol{E}$ - $V, 71 / 46$, f. 12. Manuscrito por Miguel Gómez Camargo.

No obstante, en los folios inmediatamente siguientes de ese mismo borrador encontramos una nota que aclara la indudable vinculación de la tonada con la intervención de Anteros en la segunda jornada de La fiera, el rayo, la piedra, ya que Miguel Gómez Camargo apuntó en el margen superior, de su puño y letra la siguiente rúbrica: "Sobre Anajarte, a 8. A la Asunzión". Efectivamente, en los ff. 12v-13 encontramos una responsión para 8 voces (S 1, 2, A, B; S 1, 2, A, B) casi sin texto literario en su práctica totalidad ${ }^{8}$, sobre la misma melodía de la tonada "Ama al que ama".

6 No aparece en LÓPEZ-CALO (2007), dado que en el momento de realizar su trabajo el cuadernillo no se encontraba incluido - quizá por carecer de título - en el Legajo 71 del archivo musical de la catedral de Valladolid $(\boldsymbol{E}-V)$. Por ello, lo hemos situado al final del legajo y otorgado como signatura el número correlativo a la serie de Borradores de villancicos conservada, numerándolo como 71/46.

7 Aunque el ejemplo solo muestra los principios de ambas melodías, en la fuente aparecen completas, tal y como se ve en la reconstrucción de la escena en cuestión, que figura como Apéndice 3 del presente trabajo.

$8 \mathrm{El}$ único fragmento de texto que copió el maestro de capilla en la partitura corresponde al final del tercer verso y todo el cuarto verso de la seguidilla del estribillo, que reza: “... no, / pero glorias sî”. Aunque
Ya en un trabajo publicado hace veinticinco años ${ }^{9}$, como más tarde en mi capítulo "La música en el teatro clásico" 10 aludí someramente a la existencia de esta fuente musical en el archivo musical de la catedral de Valladolid, pero creo que, por su importancia, demanda un estudio un poco más detenido. Al contrario que el resto de los borradores que Miguel Gómez Camargo legó a la "librería" de la catedral pinciana, que llevan en su portada una entrada manuscrita del propio maestro de capilla en el que se especifica como mínimo la festividad para la que fueron copiados y el año de su composición, en el presente cuadernillo no encontramos referencia cronológica ni ocasional alguna, presentando en la portada solamente pruebas de pluma ${ }^{11}$. El estudio de los contenidos del citado borrador nos confirma, efectivamente, que se trata de un caso del todo particular. Así pues, un somero examen de la fuente en cuestión pone de manifiesto que estamos frente a un cuaderno de villancicos, pero sus contenidos difieren claramente respecto al resto de la colección que integra el legajo 71. Mientras que los cuarenta y cinco borradores anteriores están asociados a las festividades ya de Navidad o ya del Corpus Christi de diferentes años a lo largo de la segunda mitad del siglo XVII -independientemente de que incorporen ocasionalmente otros materiales poéticos y musicales ajenos a esas festividades en concreto- éste está dedicado fundamentalmente, aunque no exclusivamente, a diferentes fiestas de la Virgen (Asunción, Concepción, Purificación, Virgen de la Cerca, más un Magnificat), a los Santos (San Antonio de Padua, Santa Marina, San Juan Bautista, Santiago, santa Ana, san Agustín, san Bernardo, san Juan Evangelista, san Francisco o santa Isabel) o a otras festividades ocasionales ("para un velo", "para un misacantano"). Sólo en la segunda parte del borrador aparecen de forma residual unos pocos villancicos de Navidad, al Nacimiento de Jesucristo, más uno a los Reyes y otro al Santísimo Sacramento. Es decir, la mayor parte de sus contenidos estaban destinados no a los ciclos principales de las festividades religiosas de la época, sino a festividades particulares, muy probablemente no afectas por la necesidad de continua y obligatoria renovación que regía en los villancicos de Navidad y Corpus, que necesariamente debían ser nuevos cada año en la mayor parte de las catedrales españolas. Por ello debe ser que no está asignado a una festividad ni un año en concreto. Con respecto a otro aspecto crucial, esto es, la cronología del borrador en cuestión, poco podemos apuntar, salvo que una de las piezas en él incluidas - y concretamente la que sigue inmediatamente al villancico a 8 a la Asunción, sobre

pueda parecer del todo irrelevante tal información, al menos demuestra la existencia de un contrafactum a la Asunción más de los aquí estudiados, dado que en ninguno de ellos figura ese verso; puesto que el juego de partichelas no se ha conservado, y tampoco se conoce tal texto literario, no es posible reconstruir el villancico, aunque musicalmente esté completo.

9 CABALLERO (1993): 2960-2961.

10 CABALLERO (2003): 693-694.

11 En ellas se encuentra su nombre de pila, "Miguel", y la descripción de una plantilla vocal: " 2 contraltos, 2 tiples, 2 tenores, 2 bajos", por tanto, nada que sea relevante para esta investigación. 
Anajarte - presenta, en el juego de partichelas correspondiente, sito en el mismo archivo, bajo la signatura 64/26 $6^{12}$, la fecha de 1655 , lo que nos proporciona una cronología bastante plausible para el citado cuadernillo y sitúa al fragmento musical aludido como la fuente más antigua de La fiera, el rayo, la piedra, anterior incluso a las ediciones más antiguas conocidas.

Si volvemos a la tonada de Anajarte, observamos con pesar que carece de texto literario prácticamente en su totalidad y falta igualmente todo el acompañamiento continuo. A diferencia del texto literario, que puede ser fácilmente reconstruido con los diferentes ejemplares de la obra dramática, tal y como figura tanto en las ediciones antiguas como en las modernas ${ }^{13}$, el acompañamiento continuo presenta un problema diferente y real. Sin embargo, es posible presentar una propuesta verosímil de reconstrucción del acompañamiento basándonos en una serie de concordancias musicales que se localizan en el propio archivo musical vallisoletano, dado que Miguel Gómez Camargo utilizó ambas melodías en diferentes versiones "a lo divino" a lo largo de su trayectoria, y en esas versiones sí que figura un acompañamiento absolutamente compatible con la tonada "Ama al que ama, Anajarte" y el parlamento de Anteros "El correspondido Amor". Que este acompañamiento fuera compuesto por el propio Camargo o que fuera el original que acompañaba a la tonada en su estreno teatral es una cuestión que no creo que se pueda resolver de forma incontrovertible, aunque personalmente pienso que muy bien puede tratarse del acompañamiento original ${ }^{14}$. En cualquier caso, quede claro que el acompañamiento que figura en la reconstrucción de la escena no es producto actual del que esto escribe, sino que sigue punto por punto el que utilizó el recopilador de la fuente vocal - estrictamente contemporáneo del verdadero compositor, sea quien fuere, de la obra- Miguel Gómez Camargo, en sus versiones "a lo divino".

\section{LAS VERSIONES “A LO DIVINO” DEL TONO DE ANTEROS}

En el archivo de la catedral de Valladolid $(\boldsymbol{E}-V)$ encontramos varias fuentes poéticas y musicales que se relacionan de un modo u otro con el tono del Amor correspondido, a saber:

A) En un legajo de textos de villancicos que se conserva en el archivo de la catedral de Valladolid (aunque no en su

12 Se trata del villancico a 8 (S 1, 2, A, T; S, A. T, B; arp) a san Agustín, A la gala [del bravo más fuerte]. Aunque aparece como anónimo en el juego de partichelas, su localización en el borrador y la particular grafía con que están copiadas las diversas fuentes invita a atribuirlo a Miguel Gómez Camargo. Véase LÓPEZ-CALO (2007): 386, nº 3.642.

13 Fundamentalmente Excelmo, Excelentisimo y Vera Tassis para las primeras - descritas en EGIDO, 1993: 123-124- y para las segundas, EGIDO (1989).

14 En la reconstrucción de la escena que figura en el Apéndice 3 el acompañamiento, como el resto de los pasajes "deducidos" por el transcriptor, figuran editorialmente con el mismo tipo de caracteres, pero de un tamaño ligeramente menor al de los elementos que sí aparecen explícitamente en las fuentes. sección de música) y que catalogamos hace años el entonces archivero, Jonás Castro Toledo, y yo mismo, bajo la signatura III:3/81 encontramos una trova al Santísimo Sacramento del tono de Anteros, "Ama al que ama salvarte", con las coplas "El sacramentado Dios". El texto figura en una cuartilla manuscrita por el padre fray Lucas Bueno, colaborador habitual de Miguel Gómez Camargo en la redacción de los textos de sus villanci$\cos ^{15}$. Como puede contemplarse en el Apéndice 1, la adherencia de la trova al modelo calderoniano es bastante notable (hemos destacado en negrita los términos coincidentes en ambas versiones), tanto en el estribillo como en las coplas. Esta versión al Santísimo no se ha conservado en formato de partichelas en el archivo musical de la catedral de Valladolid.

Sin duda, fray Lucas Bueno tuvo acceso no sólo a los textos, sino también a la música de muchos de los tonos de comedias que se cantaban en Madrid en las décadas centrales del siglo, ya que fue el autor (¿o quizá sólo el copista?) de un buen número de contrafacta de secciones musicales pertenecientes a los dramas mitológicos calderonianos de mitad de siglo y de otras fiestas cortesanas coetáneas, aparte de otros pertenecientes a entremeses, bailes y tonos humanos ${ }^{16}$, y puso a disposición de Miguel Gómez Camargo sus versiones "a lo divino" para que elaborara sus propios villancicos. Por otra parte, algún modo hubo de discurrir para trasmitir no solo el texto por él divinizado, sino también para hacer llegar al maestro de capilla las melodías originales de los tonos "humanos" y "de comediantes" en los que se basaban sus poemas.

B) En el archivo musical de la catedral de Valladolid se localizan, además, varias fuentes musicales que se relacionan con el tono de Anteros de diversos modos, aunque todos ellos entran dentro de la denominación que el propio Camargo utilizaba de "villancicos sobre la tonada" a saber:

b.1) $\boldsymbol{E}-V, 71 / 46$, ff. 11v-12: Parece un primer esbozo o ensayo de contrafactum. Se trata de un fragmento de una responsión a 8 voces (S 1, 2, A, B; S 1, 2, A, B) manuscrita (en claves altas) por Miguel Gómez Camargo. Carece por completo de texto literario y de rúbricas en los márgenes, que nos proporcionarían alguna pista sobre la advocación de dicho villancico u otros particulares.

15 Aparte de los datos aportados por Alejandro Vera sobre este importante personaje de la comunidad carmelitana - véase VERA (2002): 425 - son pocos más los datos que conocemos de él: ejerció el cargo de prior del Convento del Carmen Calzado de Valladolid en fechas coincidentes con el magisterio de capilla de M. Gómez Camargo en dicha ciudad, y aparece como censor de los Apothegmas en roman$c e . .$. , escrito por Tomás de Llamazares, de la Orden de san Francisco, dedicados a Juan Gaspar Henríquez de Cabrera, décimo Almirante de Castilla, y publicados a costa de Juan Antonio Huguetán y Guillermo Barbier en León de Francia, 1670.

16 En el legajo de textos de villancicos se conservan versiones "a lo divino" de tonos humanos (de Hidalgo, Marín, etc.) y "de comediantes", pertenecientes a obras dramáticas de Corte (Triunfos de Amor y Fortuna, El laurel de Apolo, La Púrpura de la Rosa, Celos aun del aire matan, Los celos hacen estrellas, Alfeo y Aretusa) y a otras piezas breves, como otras pertenecientes al Entremés del Pajarillo de Armesto y Castro, o el Baile de las flores, de Alonso de Olmedo. 
b.2a) $\boldsymbol{E}-V, 71 / 46$, f. 12 v-13: "Sobre Anajarte, a 8. A la Asunción". Responsión policoral, a ocho voces (S 1.2, A, B; S 1, 2, A, B), copiada en claves bajas, correspondiente a la seguidilla que hace de estribillo en el tono de Anteros. Manuscrita por el maestro de capilla de Valladolid, carece también del texto literario, excepto en un pequeño fragmento del A Coro 1, en donde figura el verso "no, / pero glorias sî". Este fragmento no permite, desde luego, reconstruir el estribillo del villancico, pero al menos sí documentar que se trata de una versión "a lo divino" diferente del resto de las que hemos localizado y desconocida hasta la fecha; tampoco se ha conservado en el archivo el correspondiente juego de partichelas, por lo que lamentablemente la obra está incompleta desde el punto de vista literario; no así desde el punto de vista musical, dado que, como en el resto de villancicos "sobre la tonada" de este compositor, bastaría con añadir la tonada original antes de la responsión y la sección de coplas después de ella.

b.2b) $\boldsymbol{E}$ - $V$, la música de la 56/57: Villancico de Navidad, al Nacimiento, Llore, pues siendo amante / mi Niño feliz, a 8 voces (S, A, T, B; S, A, T, B) y acompañamiento al arpa. El juego de partichelas fue copiado por un copista profesional al servicio de la catedral, con unas pocas intervenciones de Miguel Gómez Camargo ${ }^{17}$; la música de la responsión es prácticamente igual a la del villancico a la Asunción conservado sin texto citado anteriormente. Ambas constan del mismo número de compases y el mismo tratamiento policoral del estribillo, pero difieren en algunas cuestiones significativas, como son la adaptación de un conjunto policoral Coro 1 : S 1,2, A, B; Coro 2: S 1,2, A, B a otro Coro 1: S, A, T, B; Coro 2: S 1,2, A, B y la distribución de los coros, de modo que en algunas secciones el Coro 1 en la partitura es en el discurrir de la obra, igual al Coro 2 en las partichelas, amén de otras diferencias puntuales (octavaciones, unísonos,... con el fin de adecuarse mejor a la tesitura de las voces de cada conjunto vocal).

En resumen, con la música del villancico (tonada, responsión y coplas) localizada en $\boldsymbol{E}-V, 71 / 46$, ff. 12-13, Miguel Gómez Camargo ensambló dos villancicos diferentes: en primer lugar, tal y como reza el citado Borrador, un villancico para la festividad de la Asunción de la Virgen, que probablemente date del año $1655^{18}$, cuyo texto - salvo el cuarto verso del estribillo - se ha perdido irremisiblemente, ya que tampoco se ha conservado el correspondiente juego de partichelas, por lo que su edición resulta de todo punto impracticable; y en segundo lugar, una versión o trova de Navidad, al Nacimiento, Llore, pues, siendo amante, que presenta la misma música de 71/46 pero diferentemente "repartida" entre las voces y coros intervinientes; en este caso, el juego de partichelas y, por consiguiente, el texto literario completo del contrafactum sí que se han conservado, lo que permite su edición e interpretación.

17 LÓPEZ-CALO (2007): vol 2, 151, n 3.001, afirma que las partichelas son autógrafas, opinión que no comparto.

$18 \mathrm{Me}$ baso, para lanzar esta hipótesis relativa a la cronología de este Borrador de Camargo en que el villancico a san Agustín, A la gala [del bravo más fuerte], que Miguel Gómez Camargo incorporó en los ff. $13 \mathrm{v}-14$, inmediatamente después del que me ocupo, sí aparece con esa fecha, escrita por el maestro en la portada del correspondiente juego de partichelas, que se encuentra en $\boldsymbol{E}-V, 64 / 26$.
La última sección consta de ocho coplas de romance, todas ellas cantadas por el alto del primer coro con acompañamiento de arpa. Nótese que el valor de las figuras aparece duplicado respecto a la copia de la melodía en $\boldsymbol{E}-V, 71 / 46$, f. 12.

Es necesario subrayar que la adherencia del poeta contrafactista de este villancico navideño respecto al texto original calderoniano es prácticamente nula, quedando reducida a la utilización del mismo metro y rima (oxítona, en -i) tanto en el estribillo como en las coplas.

La edición de parte de este villancico de Navidad figura en el Apéndice $2 \mathrm{a}$.

b.3.1) $\boldsymbol{E}-V, 71 / 17^{19}$, ff. 22v-23v: "A la assunzión de Nuestra Señora”: Cante amor hoy la gala. Manuscrito por Miguel Gómez Camargo. Incorpora la primera sección del estribillo, a solo de Tenor con bajoncillo y bajón obligados $(\mathrm{S}, \mathrm{sb}, \mathrm{ac})$, y una responsión a 8 partes (Coro 1: S 1,2, A, T; Coro 2: S, s-bajoncillo, A, bajón). No incluye la sección de coplas. Falta casi todo el texto literario, salvo los fragmentos "que la muerte...", "en contienda..." y "que obedece". Dado que este villancico sí se ha conservado completo en formato de partichelas, en este caso la carencia de texto no resulta un problema insalvable para la edición del villancico. En el Borrador de los villancicos del Corpus deste año de 1668 no se ha localizado la sección de coplas.

b.3.2) $\boldsymbol{E}-V, 62 / 35$ : Villancico a la Asunción de Nuestra Señora, Cante amor hoy la gala, a 8 (Coro 1: S 1,2, A, T; Coro 2: S 1,2, A, bajón) y acompañamiento ${ }^{20}$. En las partichelas el solo inicial lo canta un Tiple del Coro 1, no el Tenor. En este caso sí que aparece la sección de coplas, en la que, como novedad, alternan las impares, a solo de Tiple y acompañamiento, con las pares, a cuatro voces ( $\mathrm{S}$ $1,2, \mathrm{~A}, \mathrm{~T}$ ), en homofonía estricta y acompañamiento, aunque tanto unas como otras se basan en la melodía de Anteros "El correspondido Amor" (esta vez copiada en valores duplicados). Las variantes que pueden observarse entre 71/15 y 62/35 son mínimas.

Aunque se basa en las mismas melodías esta versión es completamente diferente a la del villancico navideño, presentando ésta un tratamiento singular de la tonada inicial, al acompañarse de bajoncillo y bajón, que editamos en el Apéndice 2b, y una responsión bastante menos extensa, pero musicalmente más variada, menos reiterativa que en el resto de las fuentes musicales. Las coplas, no incluidas en la partitura autógrafa, reciben un tratamiento ligeramente diferente, ya que alternan monodia y polifonía. También es diferente respecto al modo: la presente obra se presenta a la quinta superior (finalis en LA).

Así pues, en la catedral de Valladolid se encuentran versiones "a lo divino" del tono de "Anteros" no sólo para

19 Se trata del Borrador de los villancicos del Corpus deste año de 1668. En su catálogo LÓPEZ-CALO (2007): vol. II, 102, consigna el título "Cante de amor la gala", A la Asunción de Nuestra Señora. No describe las tesituras de las voces, pues dice que "parece que es a 8 voces, pero no se ve claro".

20 LÓPEZ-CALO (2007): vol. 2, 269-370, no 3.595, yerra en la descripción de las tesituras del Coro 2 y en la datación, pues consigna 1682 como fecha del villancico (a no ser que tal fecha denote que fue cantado nuevamente catorce años después). El villancico realmente data de 1668. 
las dos festividades más importantes del año litúrgico en la España barroca, la Navidad y el Corpus (para esta última sólo el texto, de fray Lucas Bueno, aunque podría adaptarse fácilmente a alguna de las versiones musicales conservadas), sino también para la festividad de la Asunción de Nuestra Señora, principal advocación mariana en la catedral de Valladolid, todo ello en un intervalo de tiempo de quince años aproximadamente.

\section{OTRAS FUENTES POÉTICAS RELACIONADAS}

Más allá de los límites de la catedral de Valladolid también se difundió el tono de Anteros como un simple tono "humano" para cantar, descontextualizado totalmente de la comedia a la que pertenecía. Como tal lo encontramos en:

1. $\boldsymbol{E}-\mathbf{M n}, \mathrm{MS} .3661$, manuscrito facticio procedente de la biblioteca del Duque de Uceda que incorpora diversas piezas de teatro, poesías, etc. En el f. 212 aparece, bajo la rúbrica "Anteros solo", el tono en cuestión.

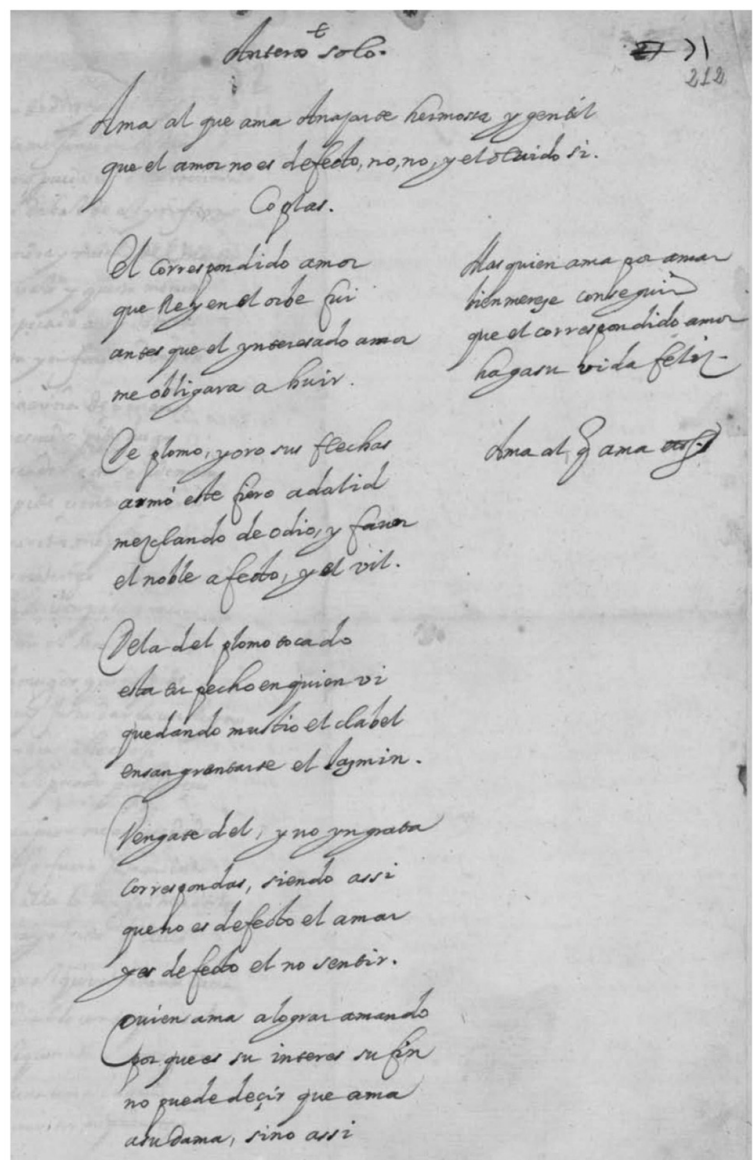

E-Mn, MS 3886, Poesías castellanas varias, vol. III, [8], f. 19v [Romance].
2. $\boldsymbol{E}-\mathrm{Mn}$, MS 3886, Poesías castellanas varias, vol. III, [8], f. 19v [Romance].

3. $\boldsymbol{E}$ - $B b c, \mathrm{MS} 1586^{21}$, p.. 73, [115]. Aparece una letra para cantar, estructurada en estribillo y coblas: E: Ama al que ama, Anagarta / hermosa y gentil. C: ¿Quién eres, joven illustre, / que entre nubes de neblí? Como puede advertirse, presenta como primera copla la estrofa de romance que originalmente recitaba Anajarte, tras la seguidilla de Anteros, y no "El correspondido Amor", mezclando de forma novedosa los parlamentos de ambos personajes, lo que induce a pensar que el recopilador no conocía la obra dramática original. Aunque una parte considerable de las "letras" incluidas en esta fuente van acompañadas de cifra catalana para guitarra, no es el caso de la poesía que me ocupa.

Así, vemos una vez más como las fuentes exhumadas en el presente trabajo contribuyen a conocer mejor los procesos de creación, difusión, circulación, asimilación y transformación de un tono de comediantes de un importante drama mitológico de mitad del siglo XVII - que originalmente tenía previsto como auditorio los propios monarcas, la nobleza vinculada a la corte y el personal de Palacio - en un tono "a lo humano" para cantar frente a espectadores menos encumbrados, vigente en los repertorios tanto en Madrid como en Cataluña ${ }^{22}$ al menos hasta finales del siglo XVII, así como en villancicos y tonos "a lo divino", a diversas advocaciones, que sonaron en determinadas iglesias del reino a lo largo del tercer cuarto del siglo XVII. De esta manera puede ponerse de relieve tanto la pervivencia como la ductilidad o maleabilidad de los materiales poéticos y musicales que se producían en la cultura española de la Edad Moderna, y que tenían en numerosas ocasiones al teatro cortesano como impulso original, sin que resulte adecuado, a mi juicio, calificar de un modo peyorativo a los productos resultantes como plagios. Cada ocasión festiva, ya profana o ya religiosa, de la España barroca tiene su público, su "escenario" y su modo de expresión propio, más o menos popular según las circunstancias, al que se amoldan las creaciones poético-musicales más notables que se generaban y difundían habitualmente desde la corte. En este sentido, coincido con J. Antonio Maravall cuando afirma:

"La difusión de patrones de la literatura y del arte barrocos [...] se produce de los centros del poder social hasta los rincones apartados. Con una apreciable diferencia en el tiempo, pero que, sin embargo, permite reconocer una velocidad considerable de propagación, se difunde la cultura barroca desde aquellos puntos en que se localizan los centros de poder - generalmente, como veremos, ciudades importantes, o más aún, políticamente importantes - hasta zonas rurales

21 El MS 1586 de la Biblioteca de Catalunya $(\boldsymbol{E}-$ Bbc $)$, Cancionero poético de Domingo Gispert, es un manuscrito de finales del siglo XVII o principios del siglo XVIII que contiene, bajo el título general de "Letras" - lo que sugiere que su fin era ser cantadas - 175 poesías numeradas y una más sin numerar; algunas de ellas tienen cifra catalana de guitarra. Es una fuente estrechamente relacionada con el MS 888 de la misma Biblioteca.

$22 \mathrm{Y}$ seguramente en repertorios urbanos de otras localidades españolas, como es el caso de Valladolid. 
que viven bajo la irradiación de aquellos otros núcleos, [...] lo que confirma nuestra tesis de que no es en los medios rurales donde la cultura barroca se forma, sino en las ciudades, principalmente en aquellas que actúan con cierto carácter de capital. [...] Ésta es la clave de bóveda del sistema"23.

\section{RECONSTRUCCIÓN DE LA ESCENA ENTRE ANTEROS Y ANAJARTE DE LA FIERA, EL RAYO, LA PIEDRA}

Ante la ausencia de manuscritos de la época, y partiendo de la primera edición de la obra ${ }^{24}$, junto con las fuentes musicales que he recopilado en el archivo catedralicio vallisoletano, presento como Apéndice 3 una reconstrucción de toda la escena musical entre Anteros y Anajarte que cierra la segunda jornada del drama calderoniano.

Obviamente, la escena incorpora tanto versos hablados o declamados - en concreto todas las intervenciones de Anajarte, pero también aquellas que Anteros desgrana cuando dialoga con su altiva interlocutora - como versos cantados en boca exclusivamente del Amor correspondido. Desde el punto de vista de los contenidos, la primera canción de Anteros, que funciona a modo de estribillo, es una seguidilla de tono admonitorio, en que el dios aconseja y trata de influir en el comportamiento y en la voluntad de Anajarte, para que olvide el desdén y ame, la cual se repite cuatro veces y "tiñe" con ese afecto todo el final de la segunda jornada. En la segunda canción ${ }^{25}$,"El correspondido Amor", Anteros se da a conocer él mismo, como contrapunto a las características y atributos del Amor interesado, cuyas flechas de plomo han herido el corazón de Anajarte; continúa instando a ésta a vengarse de Cupido, proponiéndole que, con el objeto de llegar a ser feliz, opere un cambio en su comportamiento y se plegue al amor desinteresado. Como puede observarse en el Apéndice 3, ambos fragmentos musicales contrastan tanto en el compás como en los ritmos utilizados.

Es necesario subrayar que la mezcla de lenguajes hablado y cantado en una misma escena resultaba en sí misma una novedad respecto a las convenciones que gobernaban la integración de poesía y música en la comedia nueva - y que están presentes

23 MARAVALL (1975): 161-162.

24 Para la restitución del texto literario sigo, punto por punto, la edición de la Tercera parte de comedias de Don Pedro Calderón de la Barca (Madrid, por Domingo García Morrás, Año de 1664), modernizando las grafías, capitalización y puntuación. Solamente justo al final de la jornada he añadido, entre corchetes, una rúbrica que incluye la edición de Vera Tassis, 1687, y que apunta: "Va subiendo a lo alto, midiendo la música con la distancia" porque, aparte de su importancia musical y escénica, puede explicar el hecho de que los contrafacta conservados se dediquen precisamente a la advocación de la Asunción de la Virgen, estableciendo un paralelismo claro entre el ascenso al cielo del dios Anteros y la elevación de la Virgen a los cielos, aunque no deja de ser una hipótesis no comprobable.

25 En la edición de EGIDO (1989): 316-317, este parlamento no aparece en cursivas, como el resto de los textos cantados, ni tampoco encuentro en la literatura musicológica - particularmente STEIN (1993) - alusión alguna a la cualidad musical de estas seis coplas de romance (vv. 2679-2702). En aquellas concordancias que lo plasman como un tono humano o como un villancico esta sección, o sus divinizaciones, aparecen bajo la rúbrica de "Coplas". de modo masivo en La fiera, el rayo, la piedra - novedad que se asentó con firmeza en el repertorio inmediatamente posterior de la zarzuela. Así pues, en la escena en cuestión sólo el dios Anteros utiliza el canto, lo cual no implica necesariamente, como el análisis de la partitura deja claro, que se hubiera cambiado el estilo melódico tradicional español por el "estilo recitativo". El canto solístico en sí ya resultaba bastante novedoso en la escena española, y el estilo poético y musical del fragmento de Anteros no refleja influjo alguno del modo italiano de cantar que supuestamente estaba introduciendo entre los comediantes españoles Domingo Scherdo. Es más, parece obra de un compositor de honda raíz española, que utiliza no sólo metros poéticos, sino también ritmos, giros melódicos y armonías típicos de la música hispana.

\section{EL TONO DE ANTEROS EN SU CONTEXTO}

Si ampliamos un poco el contexto y echamos un vistazo a las intervenciones cantadas en los diferentes pasajes y jornadas de La fiera, el rayo, la piedra, vemos que predominan las escenas en donde se integran tanto canciones desasidas de la trama ${ }^{26}$, generalmente preexistentes ${ }^{27}$, como canciones asidas a ella, pero en la mayor parte de los casos lo hacen mediante intervenciones polifónicas de la Música o de otros personajes colectivos específicos, como las Parcas o los Cíclopes ${ }^{28}$. Todas esas intervenciones musicales debieron conformarse, sin duda, a la práctica tradicional.

Por lo que respecta a los pasajes musicales solísticos en dicho drama mitológico, aparecen, además del que es objeto de este estudio, el de una Sirena al principio de la primera jornada, que incluye una única copla de seguidilla, seguramente en estilo igualmente tradicional, y la llamativa escena musical de Venus, Cupido y Anteros, junto con sus respectivos coros (III, vv. 3460-3485), que comienza con el canto de las seguidillas "Pues que todo en los cielos ${ }^{29 "}$ ". Pre-

26 Para los conceptos de canción "desasida de la trama" y "asida a la trama" véase CABALLERO (2003): 686-688.

27 Para las referencias a la canción Tened lástima de mí véase WILSON \& SAGE (1964): 115-116. Para la canción Es verdad que yo la vi, véase la nota a pie de página relativa a los versos 2377 y siguientes que figura en. EGIDO (1989): 297-298. Además de los precedentes consignados, también aparece, ligeramente variada, en la comedia calderoniana Gustos y disgustos son no más que imaginación.

28 Probablemente la canción de las Parcas, "Dolores de parto han sido" (I, vv. 351-53), la de los Cíclopes "Teman, teman los mortales" (I, vv. 1097-1100 y ss.), los cuatros "Ninguno llegue a ser yedra" (II, vv. 2070-73) y "Si es lo hermoso el objeto" (III, 3607-3610 y 3627-3630) más la canción “¡Muera, muera el Amor vendado y ciego!” (III, vv. 3974-75, 4004-5 y 401829).

29 STEIN (1993): 135-36, en su empeño por reforzar su idea de que el recitativo en La fiera, el rayo, la piedra estaba destinado a las conversaciones de los dioses, afirma que este pasaje - que todas las ediciones prescriben como cantado, pero ninguna (incluida Vera Tassis) en estilo recitativo - utiliza heptasílabos y endecasílabos, como argumento de autoridad para defender el uso de tal estilo italiano, frente al silencio de las rúbricas a este respecto. Por otra parte, es necesario aclarar que no se trata de endecasílabos y heptasílabos, sino de coplas de seguidillas, lo que echa por tierra, al menos en estas fechas, la convención de que una determinada métrica italianizante y estilo recitativo iban de la mano. 
senta un diálogo enteramente cantado entre los tres dioses, punteado al final por los coros que acompañan a Anteros y Cupido, pero la estructura estrófica y el metro utilizado invitan a pensar que debió utilizarse un lenguaje musical decididamente español, en cierto modo similar al usado por Anteros al dirigirse a Anajarte, e incluso de un carácter aún más ligero, menos afectivo. Aunque en ninguna de las ediciones antiguas ${ }^{30}$ ni en la moderna que manejo ${ }^{31}$, las intervenciones siguientes de Anteros, Cupido y sus coros (desde el "Hermosa madre mía" hasta el v. 3531) aparecen como cantadas, creo que existe la posibilidad - al igual que sucedía con el fragmento "El correspondido Amor" - de que lo fueran, hasta que Venus interviene de nuevo declamando una cuarteta octosilábica como solución de continuidad entre la escena musical recién acabada y la siguiente, en la que primero ambos dioses cantando a solo, y después sus coros, polifónicamente, expresan sus deseos: "Que quien no sabe querer..." y "Que quien en amar se emplea..." respectivamente. Si así fuera, estaríamos ante una escena musical de una complejidad y dimensiones inauditas en el teatro español, que prefigura claramente otras que se encuentran con cierta frecuencia en el género zarzuelístico (y también en los autos sacramentales, verdaderas zarzuelas "a lo divino") en las décadas posteriores.

Por último, resulta obligado hacer referencia a un controvertido pasaje expresado por Cupido, "Si el orbe de la Luna" (II, vv. 2014-60) que ha contribuido a dar pábulo a la idea de que con La fiera, el rayo, la piedra se inaugura la introducción del estilo recitativo en la escena cortesana española. Quede claro que en la Tercera parte de comedias de D. Pedro Calderón (Madrid, Domingo García Morrás, 1664) no aparece rúbrica alguna que aluda a que se trata de una escena cantada, y menos que especifique el supuesto estilo musical italiano ${ }^{32}$. Estoy convencido de que, en su estreno, este pasaje puesto en boca de Cupido era simplemente representado, sin intervención musical alguna, y sólo posteriormente, a raíz de alguna de las reposiciones del

30 Las breves y elípticas rúbricas de los impresos teatrales antiguos que hacen referencia a las intervenciones cantadas impiden, en numerosas ocasiones, delimitar con precisión dónde terminan e incluso qué dramatis personae participan en las mismas.

31 EGIDO (1989): 359-363.

32 Sin embargo, la alusión al recitativo sólo aparece en la edición de Vera Tassis (1687), casi medio siglo después del estreno de La fiera, el rayo, la piedra. En efecto, en la página 16 encontramos la siguiente indicación: "Múdase el teatro en el de Jardín, y en medio avrá una fuente, y sobre ella una hermosa estatua, y sale Cupido cantando en estilo recitativo". Cant. Cup. Si el Orbe de la Luna, / esfera soberana / de la casta Diana / sagrado puerto fue de la fortuna / [...]. Para dar cierto peso al argumento que defiende esta idea de la introducción del recitativo en fechas tempranas, STEIN (1993): 135, alude asimismo al hecho de que tal pasaje está escrito, significativamente, en heptasílabos y endecasílabos, metros italianizantes infrecuentes en el repertorio musical español. Resulta ilustrativo el hecho de que el primer recitativo indubitablemente cantado en la corte española, perteneciente a Fortunas de Andrómeda y Perseo, "Ya, hermoso galán Mercurio", estuviera escrito en octosílabos. Parece ser que la convención de utilizar el recitativo para versos heptasílabos y endecasílabos es posterior a estas fechas: tampoco rige en Celos aun del aire matan (1660); aparece, pero de un modo no prescriptivo, en La estatua de Prometeo (1674), y sólo se va afianzando a medida que nos aproximamos al siglo XVIII. drama, se "modernizó" y se compuso ex novo la música en estilo italiano para tal fragmento, cuando el recitativo ya estaba firmemente asentado en el teatro español del siglo XVII.

Teniendo en cuenta todo lo apuntado anteriormente, creo que es mucho más probable que en el estreno de La fiera, el rayo, la piedra no se utilizara el estilo recitativo en absoluto; sólo a partir del Prólogo de Fortunas de Andrómeda y Perseo, que sanciona la plática de los dioses ${ }^{33}$, y de la rúbrica del manuscrito de Harvard en donde se explica en qué consiste el estilo recitativo ${ }^{34}$ puede afirmarse sin lugar a dudas que el "recitar cantando" se incorpora al conjunto de estilos y lenguajes musicales a disposición de los dramaturgos españoles del Siglo de Oro.

\section{BIBLIOGRAFÍA}

Bacci, Mina, "Lettere inedite di Baccio del Bianco", Paragone, 14 (Florencia, 1963): 103-132.

Caballero Fernández-Rufete, Carmelo, "Nuevas fuentes musicales del teatro calderoniano", Revista de Musicología, 16/5 (1993): 2958-2976.

Caballero Fernández-Rufete, Carmelo, "La música en el teatro clásico”, Historia del Teatro Español, Huerta Calvo, J. (dir.), Madrid, Gredos, 2003, vol. 1, 677-715.

Caballero Fernández-Rufete, Carmelo, El Barroco musical en Castilla y León: estudios en torno a Miguel Gómez Camargo. Valladolid, Diputación, 2004.

Egido, Aurora (ed.), Calderón de la Barca: La fiera, el rayo, la piedra. Madrid, Cátedra Ediciones, 1989.

López-Calo, José, La Música en la Catedral de Valladolid, vol. 2, Catálogo del Archivo de Música (Miguel Gómez Camargo). Valladolid, Ayuntamiento de Valladolid y Caja España, 2007.

Maravall, José Antonio, La cultura del Barroco: Análisis de una estructura histórica. Barcelona, Ariel, 1975.

Maestre, Rafael, edición filológica, crítica y escenotécnica de Calderón de la Barca: Fortunas de Andrómeda y Perseo. Almagro, Museo Nacional del Teatro, 1994.

Stein, Louise K., Songs of Mortals, Dialogues of Gods. Oxford, Clarendon Press, 1993.

Vera, Alejandro, Música vocal profana en el Madrid de Felipe IV: el 'Libro de Tonos Humanos' (1656). Lleida, Institut d'Estudis Illerdencs, Diputació de Lleida, 2002.

Wilson, Edward W. y Sage, Jack, Poesías líricas en las obras dramáticas de Calderón. Londres, Tamesis Books, 1964.

33 Poesía. Tu advierte que en las deidades / que introduzgas ha de haber / otra armonía en la voz / que en los humanos, que es bien / que no hablen los dioses como / los mortales... (vv. 93-98), en Calderón de la Barca: Fortunas de Andrómeda y Perseo, edición filológica, crítica y escenotécnica de R. Maestre, Almagro, Museo Nacional del Teatro, 1994: 44.

34 Harvard, Houghton Library, MS Typ 258, f. 22v: “[...] empezaron su plática [Palas y Mercurio] a diferencia de los humanos, en un estilo recitativo, que siendo un compuesto de representación y música, ni bien era música ni bien representación, sino una entonada consonancia a quien acompañaba el coro de instrumentos". Citado por STEIN (1993): 150, n. 63. 


\section{APÉNDICE 1.1. Edición comparada de los textos del contrafactum de fray Lucas Bueno y del texto original de Calderón de la Barca}

Estribillo

Ama al que ama salvarte, cristiano feliz, que el amor no es defeto y el olvido sí.

$$
\text { Coplas }
$$

1. El sacramentado Dios, que hombre en el orbe fui antes que el interesado Judas me obligase a huir.

2. En el papel de un misterio, con la oblea de mi ardid pude dos naturalezas, la humana y divina, unir.

3. De la de humano tocado ¿qué es hoy mi cuerpo feliz? Darse en bebida clavel y darse a comer jazmín.

4. Cómame el hombre y no ingrato corresponda, pues le di todo un Dios como unas flores que ha dado el mejor abril.

5. A mis finezas cruel, un apóstol infeliz mezclaba en odio y amor el noble afeto [y el vil].

6. Porque quien sigue a su Dios siendo la plata su fin no puede decir que ama a su Dueño, sino a sí.

7. Mas quien ama por amar bien merece conseguir comer siempre de esta forma sin más fin que amar sin fin.

8. Este es el Pan soberano. y sólo diga de no el hombre que no está en sí.

\section{[Estribillo]}

\section{Ama al que ama salvarte cristiano feliz, que el amor no es defeto y el olvido sí.}

5

$$
\text { (E-Vc: LTV III:3/8) }
$$
¡Venid a comer, venid!,

Ama al que ama, Anajarte hermosa y gentil, que el amor no es defecto, no, y el olvido sí.
De la de plomo tocado está tu pecho, en quien vi quedarse mustio el clavel, ensangrentado el jazmín.

Véngate de él y no ingrata correspondas, siendo así que no es defecto el amar y es defecto el no sentir.

De plomo y oro sus flechas armó este fiero adalid, mezclase de odio y favor el noble afecto y el vil.

Quien ama a lograr amando, porque es interés su fin no puede decir que ama a su dueño, sino a sí.

Mas quien ama por amar bien merece conseguir que el correspondido Amor haga su vida feliz.

Ama al que ama, Anajarte

hermosa y gentil, que el amor no es defeto y el olvido sí.

(Fiera, rayo, piedra) 
APÉNDICE 1.2. Texto del villancico de Navidad, al Nacimiento, Llore, pues, siendo amante. E-V, 56/57.

[Estribillo]

Llore, pues, siendo amante

mi Niño feliz,

que llorar no es flaqueza, - ¡no, no!-

mas fineza, sí.

Coplas

1. ¿Por qué puede Amor llorar,

si no llora, viendo aquí

el desaire de un desdén

y lo ingrato en pechos mil?

2. Despreciada una fineza ofensa en amor la vi, aunque para arder más fuego se suele un desdén mentir.

3. Quien ama a ingratos descansa en el llanto, porque así se acredita una fineza con suspirar y gemir.

4. En la estatura de inmenso te supo el amor medir, pues te ciñó con la nada de nuestro humano matiz.
5. Y allí el hombre, poco urbano, cuando se ve más feliz, o el hospedaje te niega, o te lo ofrece tan vil. de un diciembre se ve abril, descortés o ingrato, paga sus flores con nieves mil.

8. Esto, mi Niño, es amar, porque es fuerza el sufrir, que el amor correspondido se suele interés decir.

\section{APÉNDICE 1.3. Texto del villancico a la Asunción Cante amor hoy la gala. E-V, 62/35.}

[Estribillo]

Cante amor hoy la gala

en contienda feliz,

que la muerte no triunfa, - ¡no, no!que obedece, sí.

Coplas

1. Victorias en lo bizarro logra el amor más feliz cuando para vencedora hace industria del morir.

2. En mejor vida lo amante del cielo la emperatriz breve paréntesis triunfa entre uno y otro vivir.

3. Tan diáfano cuerpo mide esa región de zafir que extremos el sol y luna fueron ejemplo de eclips.

4. A coronarse por Reina surca ese hermoso cenit, que quien no cede a lo humano rompe de la ley el fin.
5. Suba en festivos aplausos de uno y otro querubín quien por amor, no por pena, hizo a la muerte lucir.

[Estribillo]

Cante amor hoy la gala que la muerte no triunfa - ¡no, no!que obedece, sí. 
Apéndice 2a. Transcripción del villancico Llore, pues, siendo amante (cc. 1-122)

\section{Llore, pues, siendo amante}

\section{Villancico de Navidad, al Nacimiento}

\section{[Estribillo] Solo y a ocho}

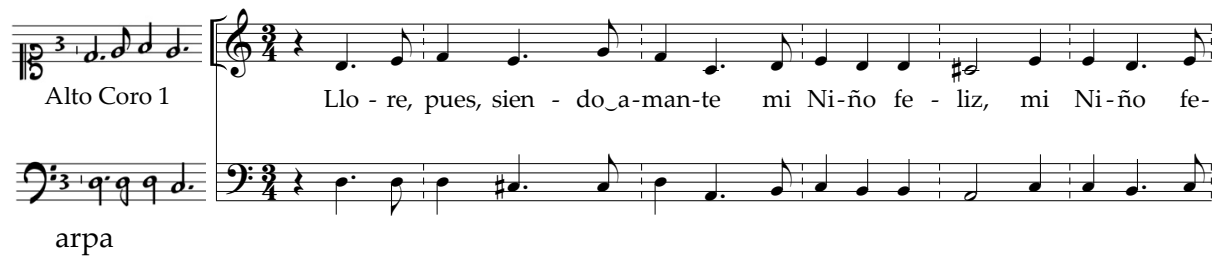

S 1

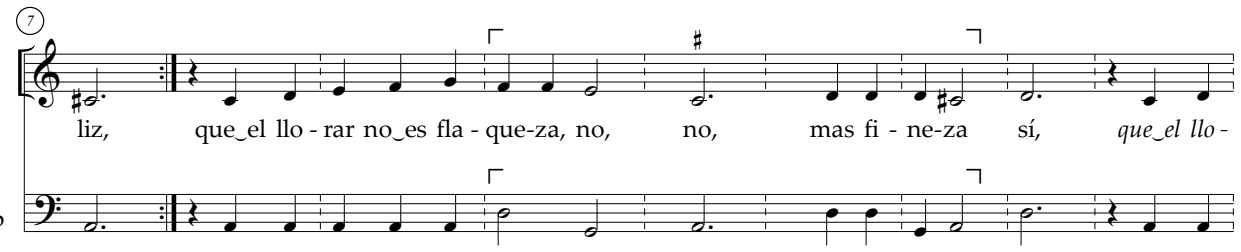

S1

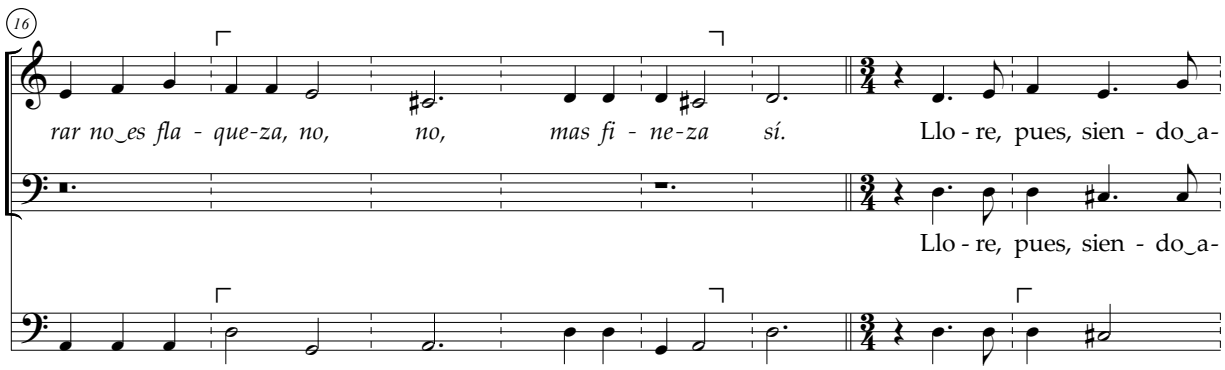

S 1

(24)

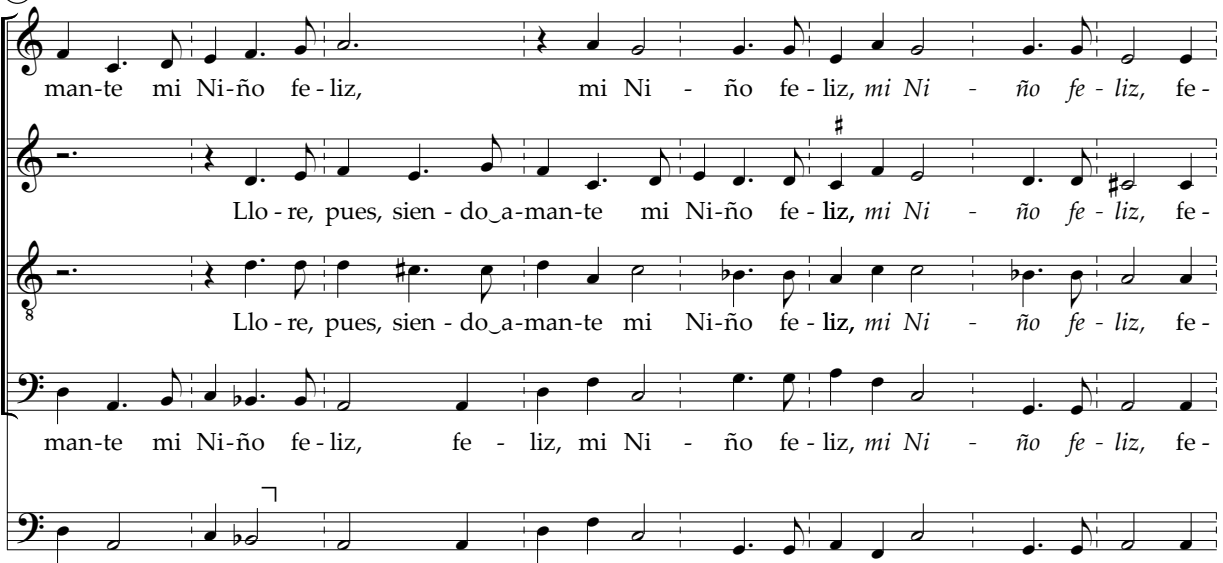



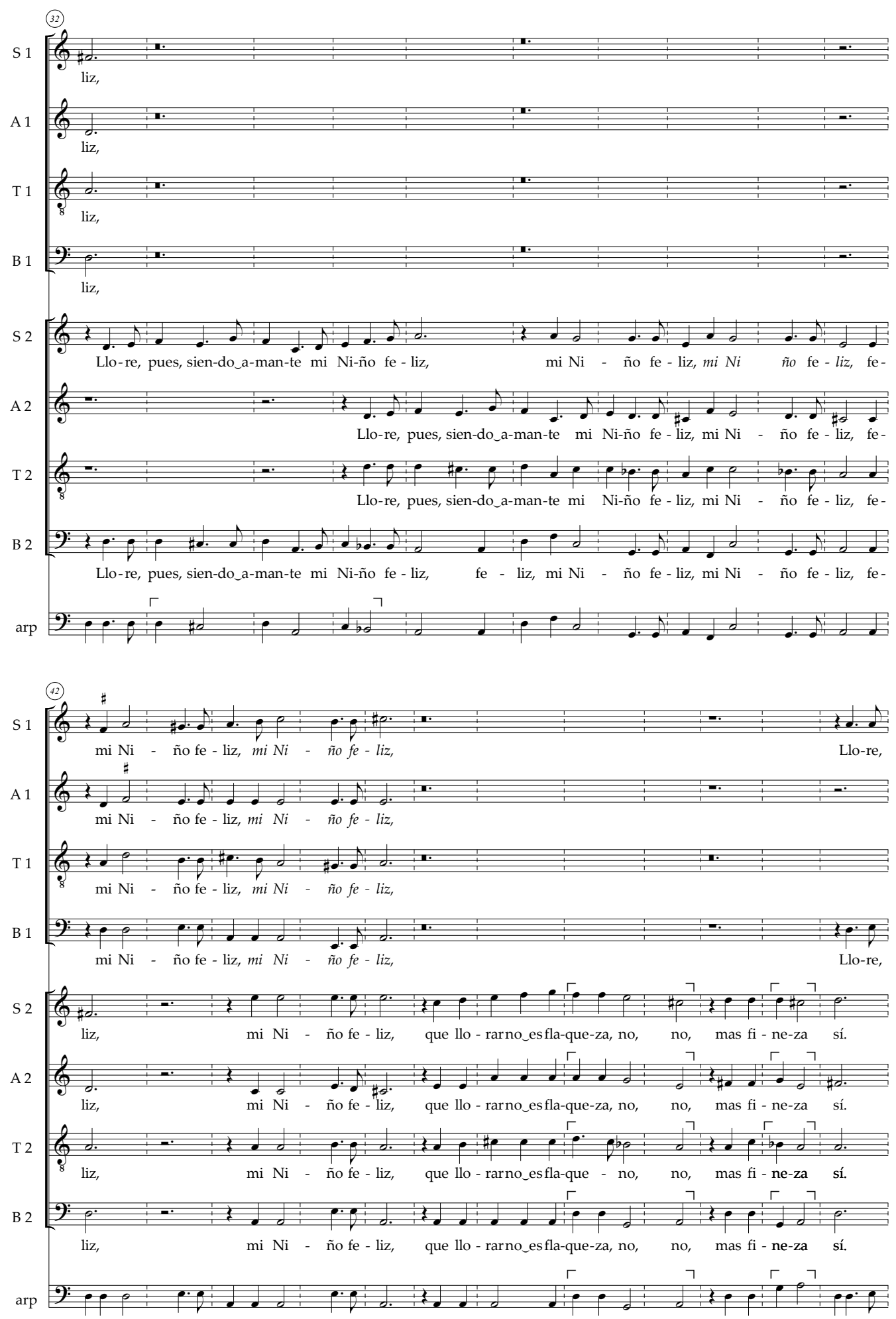

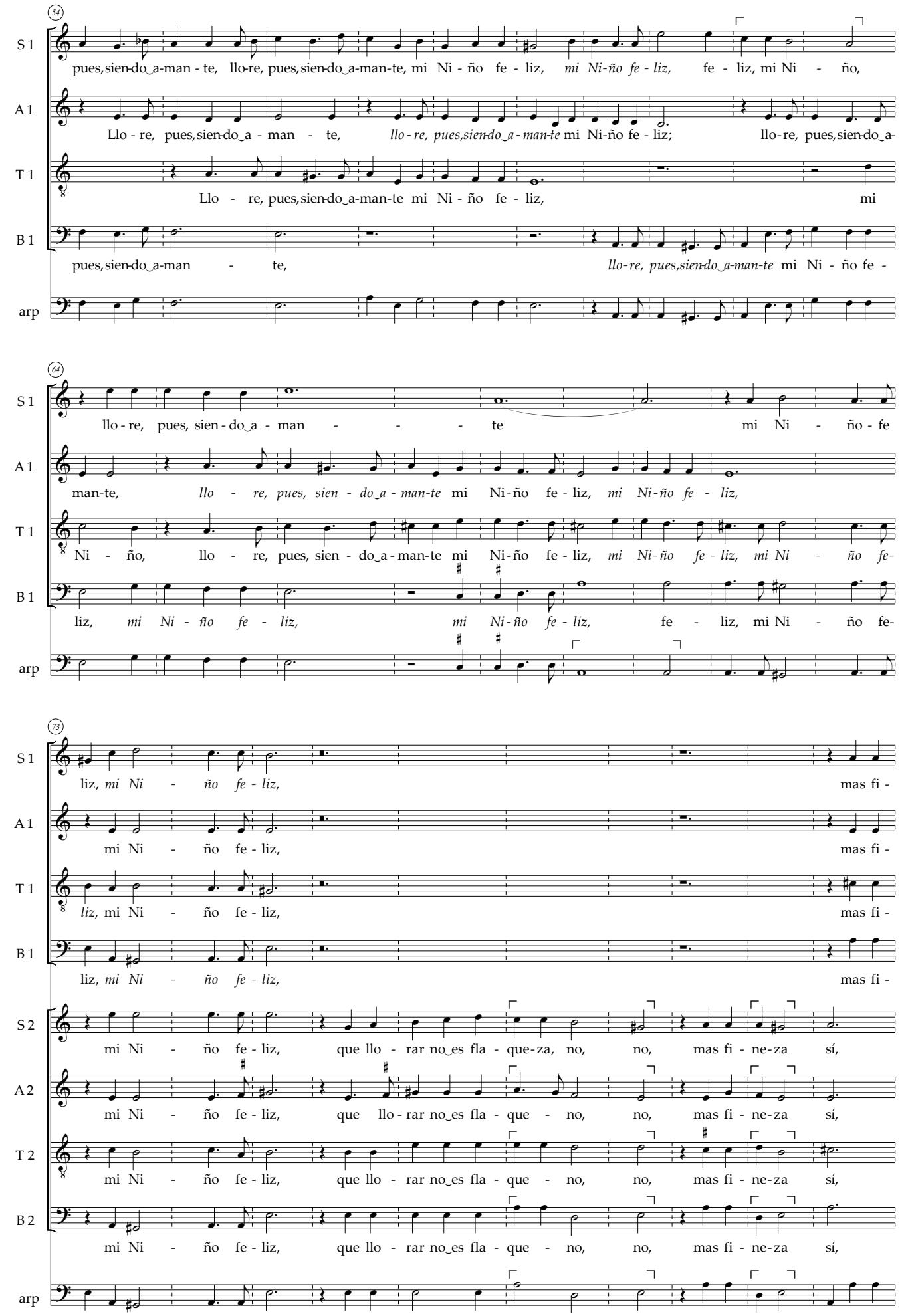

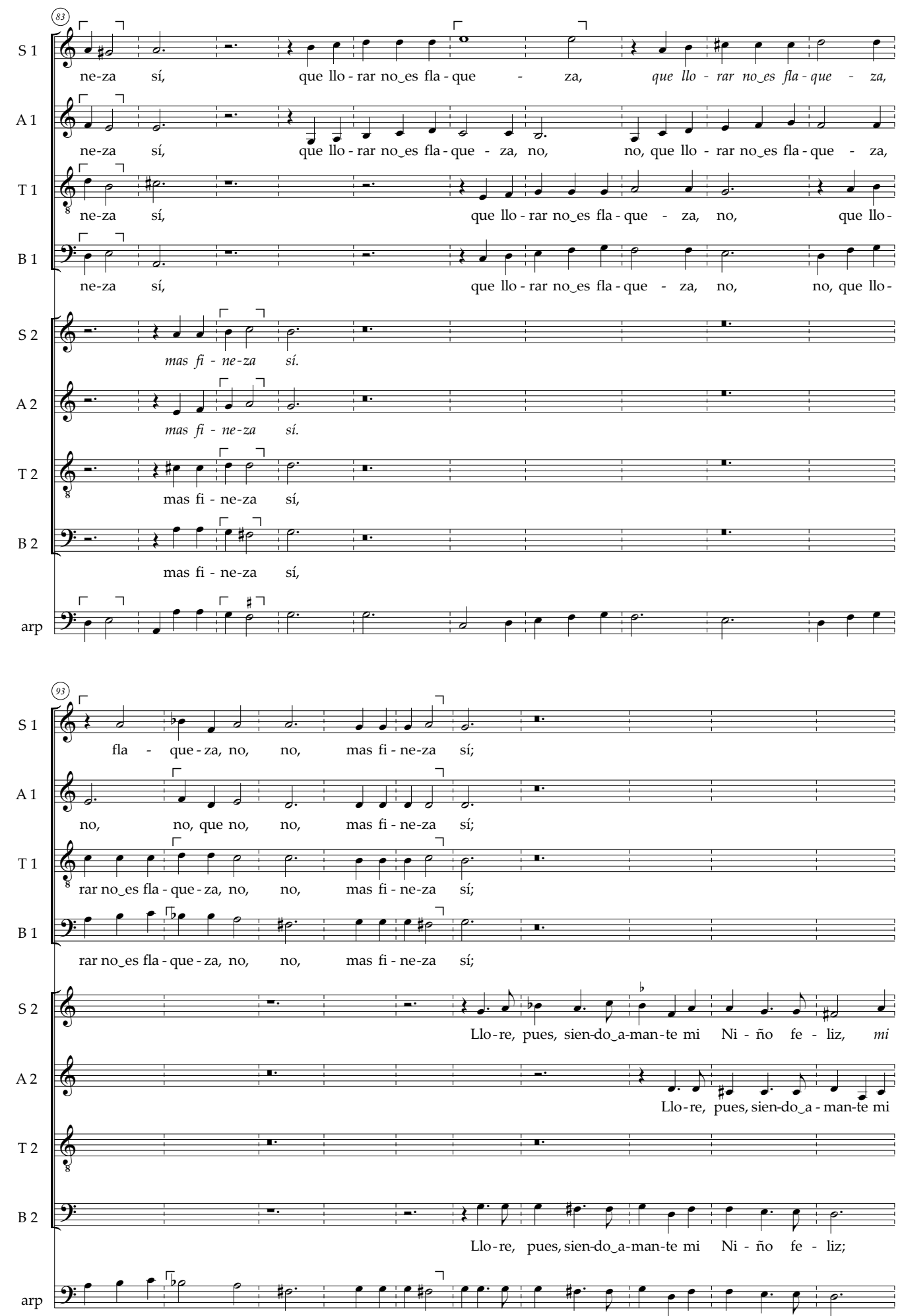

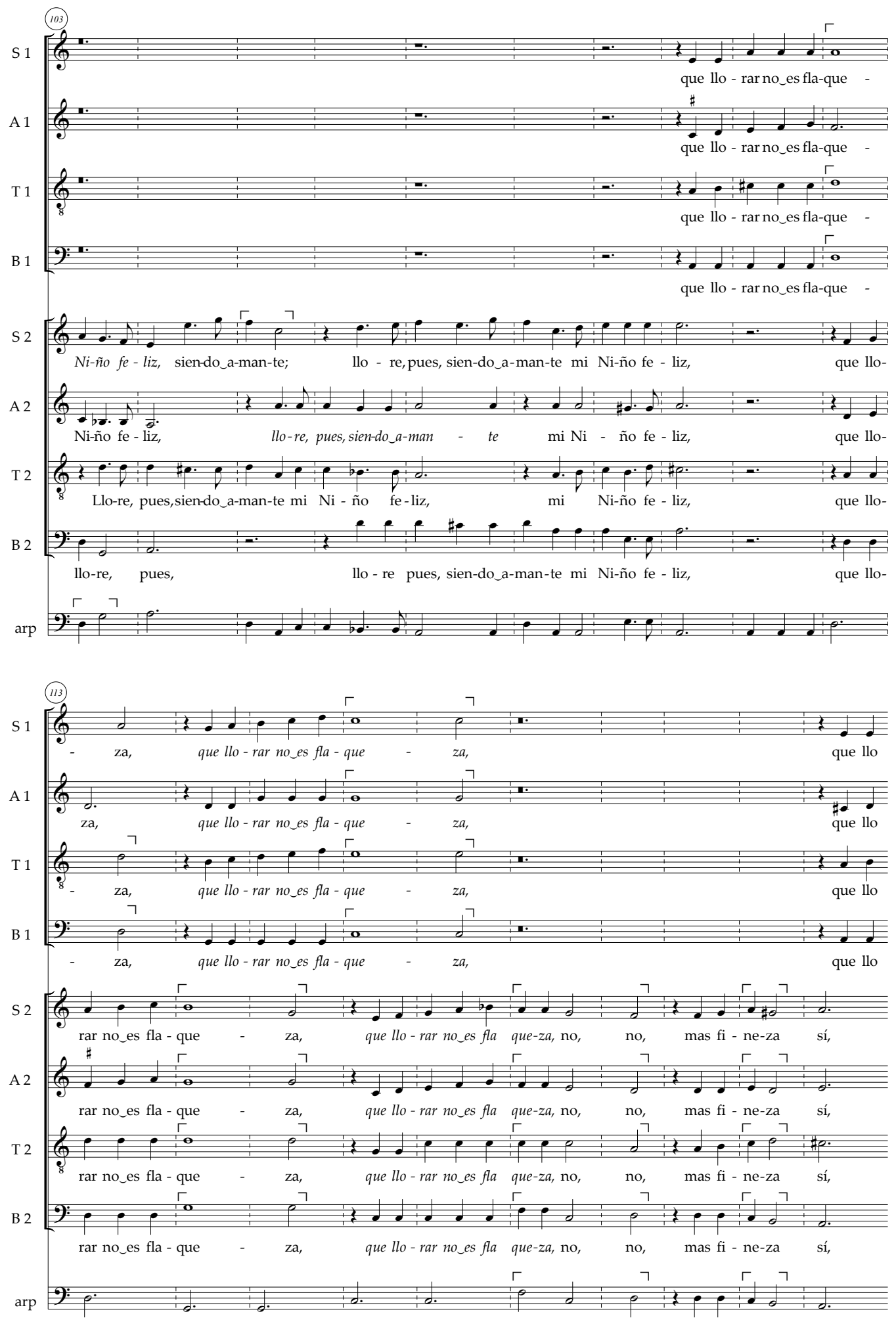
Apéndice 2b. Transcripción del villancico Cante amor hoy la gala, cc. 1-24

\section{Cante amor hoy la gala}

\section{Villancico a № Sª [de la Asunción]}

E- $V: 62 / 35$

Miguel Gómez Camargo, 1682

Tr.: C. Caballero F-Rufete

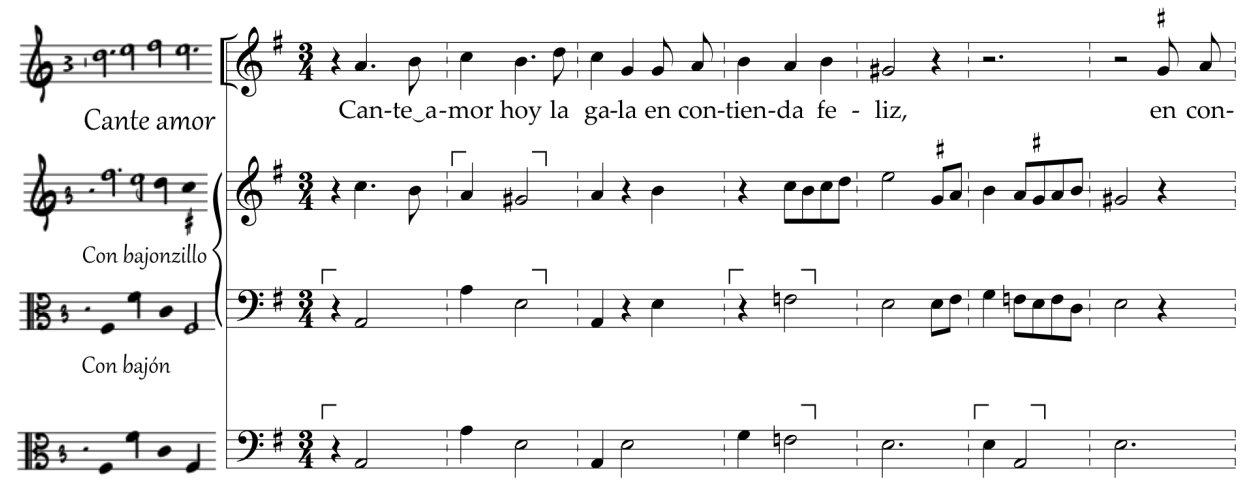

Cante amor
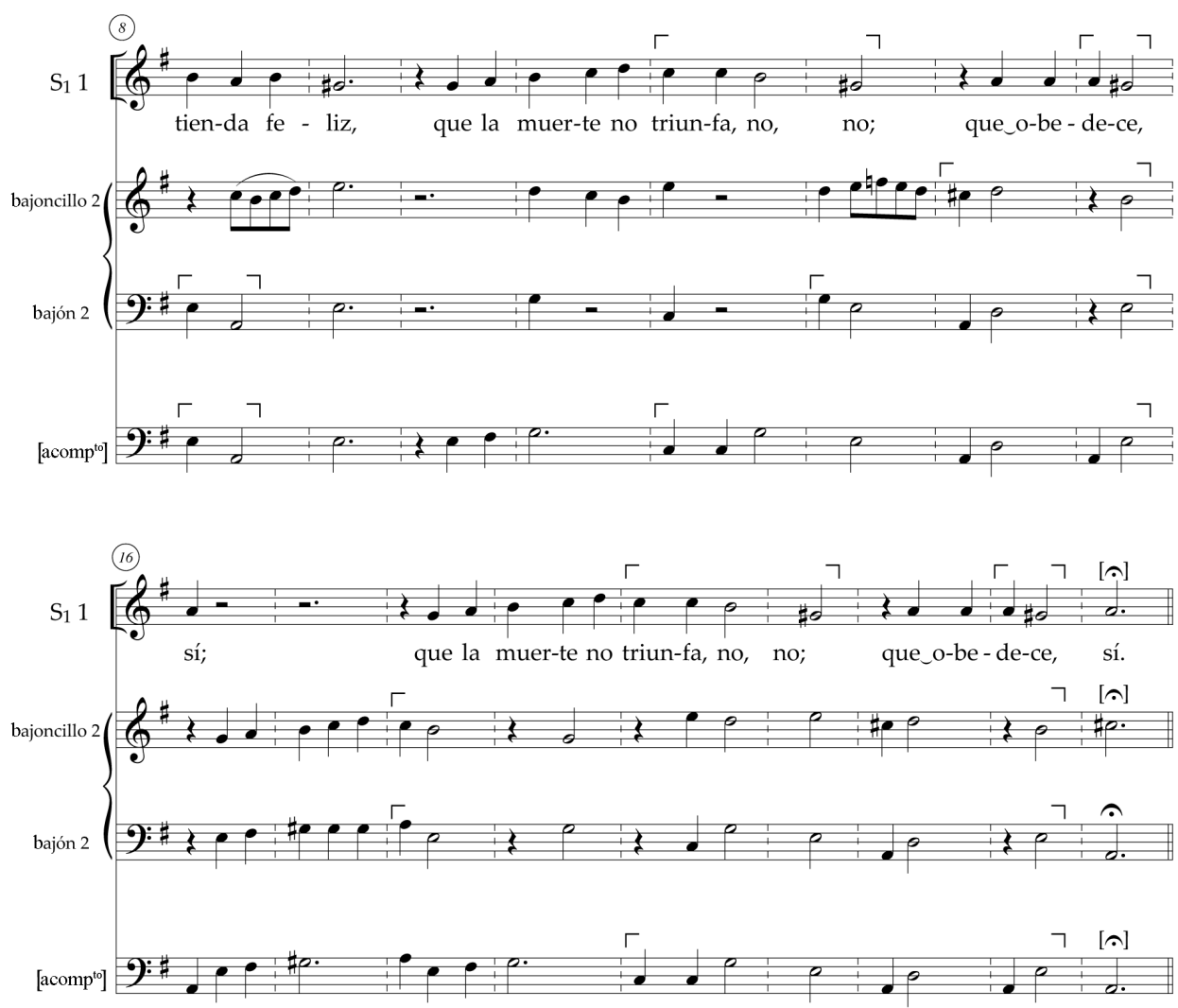
Apéndice 3. Reconstrucción de la escena entre Anteros y Anajarte

\section{Ama al que ama, Anajarte}

Calderón: La fiera, el rayo, la piedra, II, vv. 2654-2740

E-V: $71 / 46$, f. 12

ANAJARTE. ¿Habrá quién me hable de amor?

¿Habrá quién pueda decir

que corresponda ya más

yo a ningún afecto?
Anónimo [¿Scherdo?]

Tr.: C. Caballero F-Rufete

Ilusión sería, porque éste, hermosos cielos, decid, ¿sin que le formara yo pudiera él formarse?

ANTEROS.

Sí.

ANAJARTE. ¿Quién es quien así me habla, de quien sólo percibí

el eco?

Baja ANTEROS.

sin que se la dicte otro?

Dígolo porque - ¡ay de mí!-

no fue acento de mi acento

el que en los aires oí.

ANTEROS.
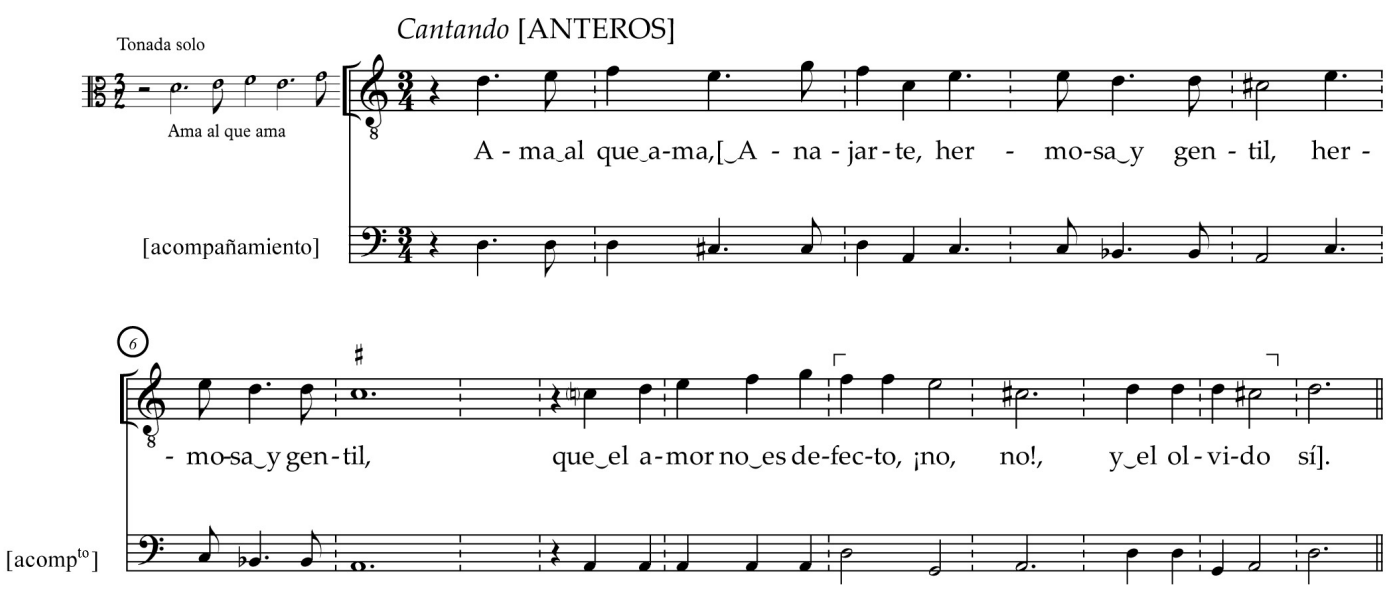

ANAJARTE. ¿Quién eres, hermoso joven,

que entre nubes de rubí

vienes desplegando hojas

de púrpura y de carmín? 

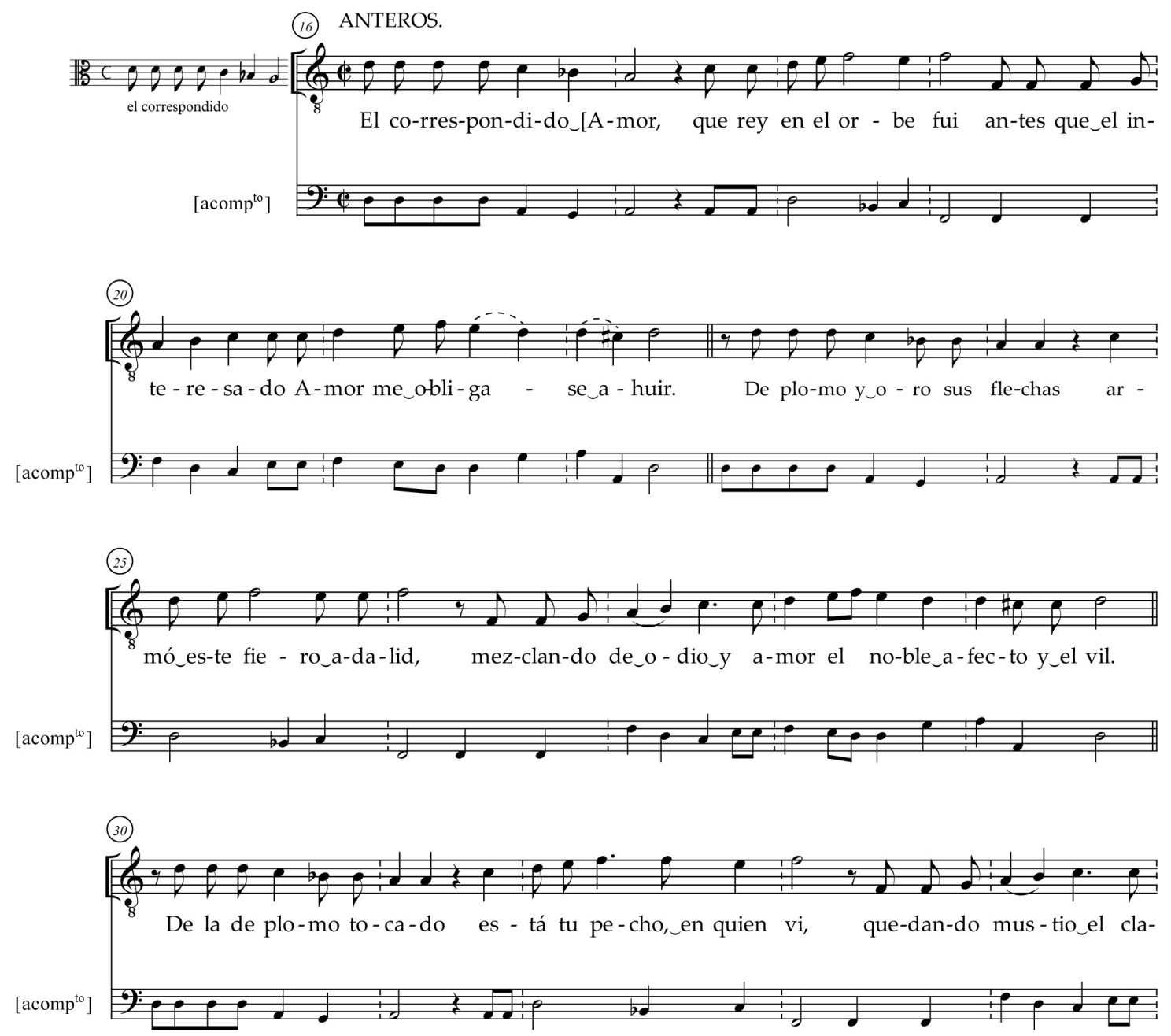

(35)

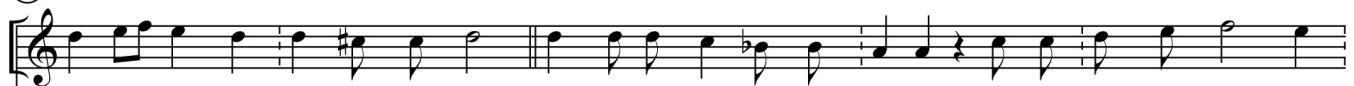
vel, en-san-gren-tar-se_el jaz-mín. Vén-ga-te de_él y no_in-gra-ta co-rres-pon-das, sien-do_a-

$\left[\operatorname{acomp}^{\text {to }}\right]$
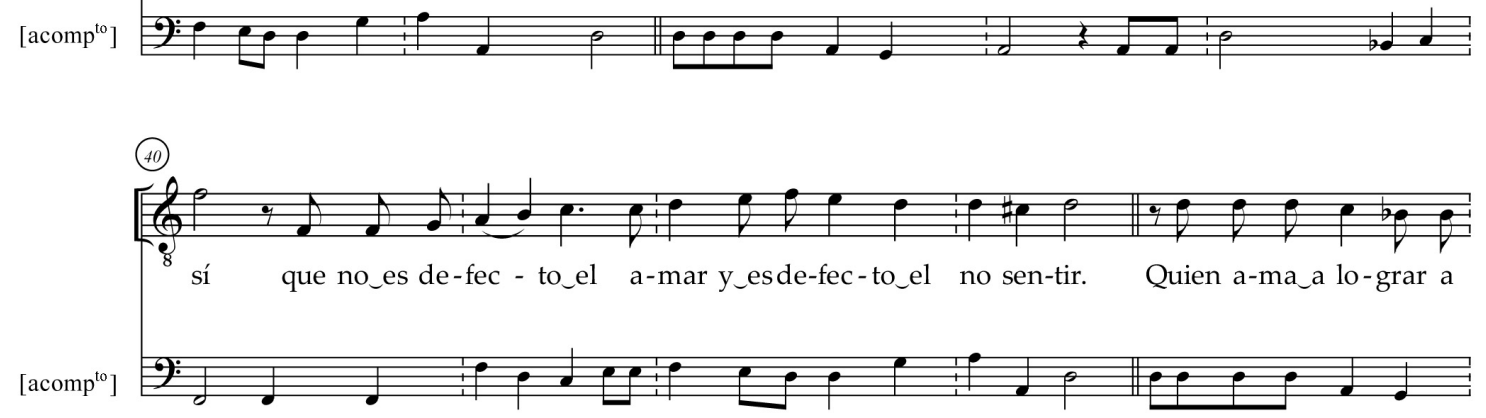

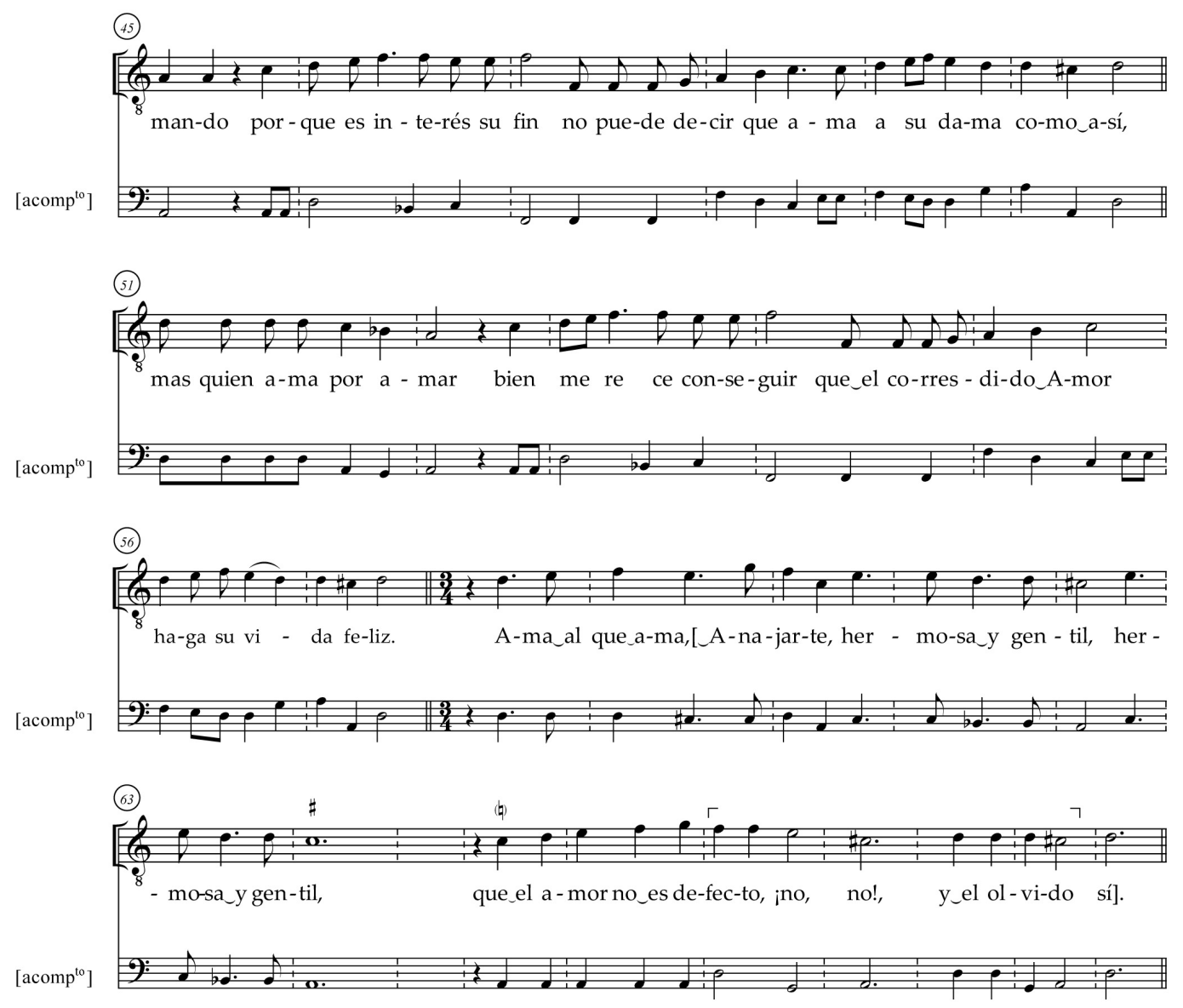

ANAJARTE. Aunque en traje de deidad del cielo te veo venir, no te he de creer.

$$
\text { ¿Por qué? }
$$

ANAJARTE. Porque no has de persuadir nunca a mi pecho que deje de aborrecer.

$$
\text { ¡Ay de ti! }
$$

ANTEROS. ¡Ay de ti!

ANAJARTE. ¿Es una amenaza?

ANTEROS.

No.
ANAJARTE. Pues, ¿qué es? ¿Es lástima?

ANTEROS.

Sí.

ANAJARTE. ¿Lástima sin amenaza?

ANTEROS. ¿Por qué no?

ANAJARTE. ¿De qué, me di?
ANTEROS. De que quien sentir no sabe merece... 

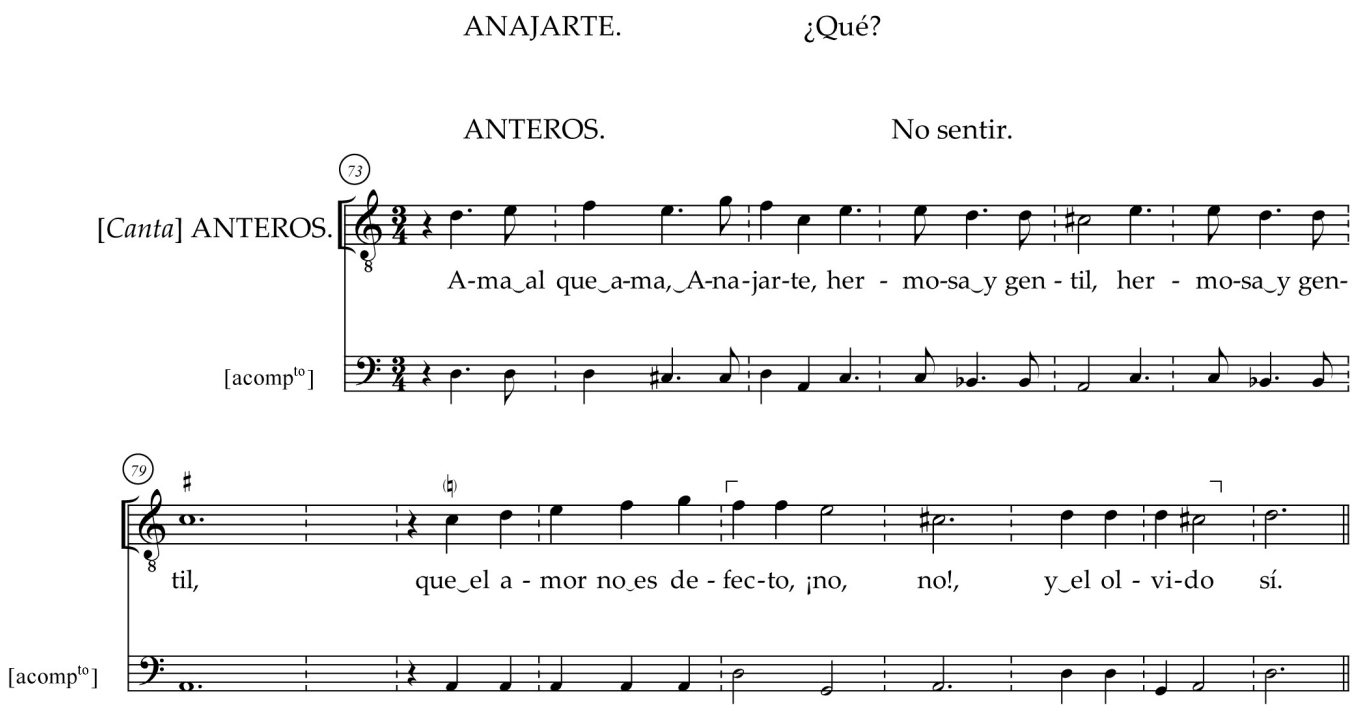

[ANTEROS]. No un tirano dios blasone

para ser rayo nací.

de que se valió de ti con nombre de rayo para

ANTEROS. Pues mira que el rayo es piedra abrasar y no lucir. después que llega a morir.

ANAJARTE. Por más que me persüadas no he de amar ni he de admitir tu correspondido Amor;
ANAJARTE. ¿Qué importa ser piedra yo?

Y no te canses, en fin, que no he de corresponder aunque más te oiga decir:
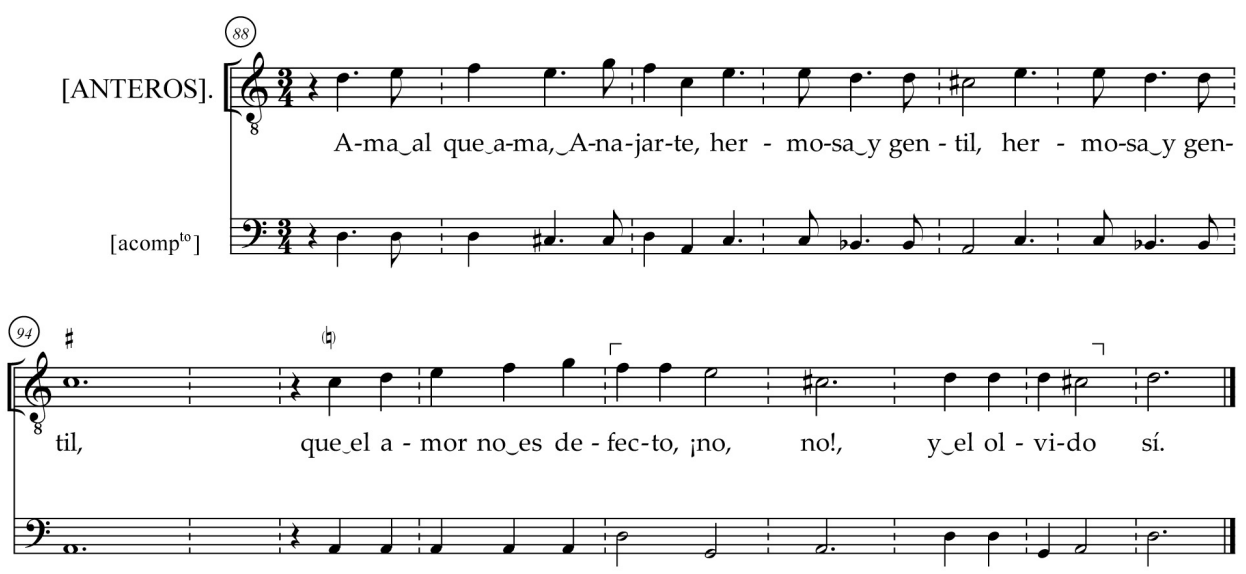

[Va subiendo a lo alto, midiendo con la música la distancia] 